\title{
ERRATUM
}

\section{Erratum to: Autologous tumor lysate/Bacillus Calmette-Guérin immunotherapy as an adjuvant to conventional breast cancer therapy}

\author{
J. Convit ${ }^{1} \cdot$ H. Montesinos ${ }^{2} \cdot$ H. Oviedo ${ }^{1}$ - G. Romero ${ }^{3} \cdot$ B. Maccarone $^{4}$. \\ E. Essenfeld ${ }^{5}$ A. Convit ${ }^{6}$ L. E. Palacios ${ }^{3}$
}

Published online: 19 April 2016

(C) Federación de Sociedades Españolas de Oncología (FESEO) 2016

\section{Erratum to: Clin Transl Oncol (2015) 17:884-887 \\ DOI 10.1007/s12094-015-1320-0}

Human study section, page 885 , second paragraph, last sentence: an incorrect unit of measurement was inserted by mistake. The sentence should read:

At the moment of vaccination, the soluble fraction of the homogenate was mixed with formaldehyde $36 \%$ at a final concentration of $0.02 \%$ and $0.06 \mathrm{ml}$ of BCG suspension $0.15 \%$ (Staten Serum Institute, Copenhagen).

This error does not change the scientific conclusions of the article in any way. The authors regret this error and apologize for any inconvenience caused.

The online version of the original article can be found under doi:10.1007/s12094-015-1320-0.

J. Convit

admin@jacintoconvit.org

1 Instituto de Biomedicina Dr. Jacinto Convit, Distrito Capital, Venezuela

2 Universidad Simón Bolívar, Sartenejas, Distrito Capital, Venezuela

3 Hospital Oncológico Dr. Luis Razetti, Distrito Capital, Venezuela

4 Cirugía General \& Mastología, Policlínica Metropolitana, Distrito Capital, Venezuela

5 Anatomía Patológica, Policlínica Metropolitana, Distrito Capital, Venezuela

6 Fundación Jacinto Convit, Caracas 1071, Venezuela 